\title{
Oxidation resistance of exogenous melatonin on leaves of kiwifruit seedlings under copper stress
}

\author{
Xuewen Zhao ${ }^{1, a}$, Hui Xia ${ }^{1,2, b}$, Yue Xie ${ }^{3, c}$, Mingzhang Li ${ }^{3, d}$, Yongzhi Wang ${ }^{3, e}$, \\ Dong Liang ${ }^{1,2, \mathrm{f}, *}$
}

${ }^{1}$ College of Horticulture, Sichuan Agricultural University, Chengdu, Sichuan, China

${ }^{2}$ Institute of Pomology and Olericulture, Sichuan Agricultural University, Chengdu, Sichuan, China

${ }^{3}$ Sichuan Province Natural Resources Science Academy, Chengdu, Sichuan, China

ad867396930@qq.com, busanxia_2001@163.com, '379291608@qq.com, 'Limzhang@163.com, e63415396@qq.com, 'liangeast@sina.com

${ }^{*}$ Corresponding author. Xuewen Zhao and Hui Xia contributed equally to this work

\section{Keywords: Kiwifruit; Copper stress; Exogenous; Oxidation resistance}

Abstract. In this study, the wild kiwifruit seedlings were used as the research object to investigate the oxidation resistance of exogenous melatonin on leaves of kiwifruit seedlings under copper stress, adopting the root irrigation method. The results showed that exogenous melatonin effectively increased the content of proline in leaves of kiwifruit seedlings under copper stress, enhanced the osmotic adjustment ability of plant cells, increased the antioxidant substances and improve the antioxidant capacity, reduced the toxicity of copper stress on kiwifruit and promote the tolerance of plants. The results indicated that exogenous melatonin could availably alleviate the toxicity of copper stress on kiwifruit seedlings and increase the tolerance of plants to heavy metal stress.

\section{Introduction}

Kiwifruit riches in Vc and has high nutritional value, known as "the king of fruits" [1]. Melatonin is a signal substance found in mammals, 1958 [2]. Studies have found that melatonin can enhance plant cells expansion in vitro, promote root growth and regeneration, maintain the integrity of the plant biofilm, and against adverse environmental damage to plants [3].

Copper is an important trace element in plant growth and development, which involved in many physiological processes of plants. But excessive copper will lead to plant poisoning, and affect the normal growth and development of plants [4]. At present, the effects of copper stress on plants are mainly studied by crops, and horticultural plants are less. Therefore, it is very important to study the effects of melatonin on plants under copper stress. This study was to investigate the physiological regulation mechanism of exogenous melatonin on kiwifruit under copper stress to provide guidance of application of exogenous melatonin in cultivation.

\section{Materials and Methods}

Materials and Treatment. The one-year-old wild Actinidia deliciosa seeds were placed at $4^{\circ} \mathrm{C}$ for 55 days, then to $4^{\circ} \mathrm{C} 16 \mathrm{~h}$ and $24^{\circ} \mathrm{C} 8 \mathrm{~h}$ variable temperature treatment for two weeks. The seeds were placed at $25^{\circ} \mathrm{C}$ for $10-15$ days to germinate. Then the seeds are sown in the moist soil, and placed in the culture room with temperature of $20-25^{\circ} \mathrm{C}$ and humidity above $40 \%$. We watered one time every morning and evening, and 1/2 Hoagland nutrient solution every week for one time. When grown 3 true leaves, the plants were moved to pots containing perlite $\left(10 \mathrm{~cm}^{*} 10 \mathrm{~cm}\right), 3$ plants per pot.

When grown up with 9-10 true leaves, the seedlings with the same growth condition were divided into control group and treatment groups. The seedlings were treated with the $50 \mathrm{~mL} 0$ and 0.1 $\mu \mathrm{mol} \cdot \mathrm{L}^{-1} \mathrm{MT}$ solution in the root irrigating for 5 days, one day at a time. The seedlings were treated 
with $15 \mu \mathrm{mol} \cdot \mathrm{L}^{-1} \mathrm{CuSO}_{4}$. A total of 3 treatments: (1) $\mathrm{CK}$; (2) $\mathrm{T} 1: \mathrm{CuSO}_{4}\left(15 \mu \mathrm{mol} \cdot \mathrm{L}^{-1}\right)$; (3) $\mathrm{T} 2: \mathrm{MT}$ $\left(0.1 \mu \mathrm{mol} \cdot \mathrm{L}^{-1}\right)+\mathrm{CuSO}_{4}\left(15 \mu \mathrm{mol} \cdot \mathrm{L}^{-1}\right)$. Middle leaves (seven to nine per plant) were sampled after 0,3 , 6,9 , and $12 \mathrm{~d}$. All collected tissues were immediately frozen in liquid nitrogen and stored at $-80^{\circ} \mathrm{C}$.

Physiological Indexes. The content of proline was determined by the method of acid ninhydrin [5]; The total phenolic content (TPC) was measured using a slightly modified Folin-Ciocalteu method [6]; The total flavonoid content (TFC) was measured using a slightly modified method of Jia et al [7]; The total flavanol content (TFAC) was determined using the p-DMACA method [8]; DPPH • free radical scavenging capacity $(\mathrm{DPPH}), \mathrm{ABTS}^{\cdot+}$ free radical scavenging capacity (ABTS) and ferric reducing antioxidant (FRAP) were measured by Du [9]; Determination of the ascorbic acid content (AsA) refered to $\mathrm{Ma}$ et al [10]. The above indicators $\mathrm{w}$ ere set three times repeats, and calculated the average.

Data Handling. Software Excel 2010 was used to calculate the test data and tabulation. Statistical analysis was performed using software SPSS. $\mathrm{P}<0.05$ indicated a significant difference.

\section{Results and Analysis}

Effects of exogenous melatonin on proline content in leaves of kiwifruit seedlings under copper stress. As seen from Table 1, after $\mathrm{Cu}$ stress treatment, the content of proline was significantly increased all over the time when compared with control. The proline content of T1 and T2 increased first and then decreased, and peaked at $6 \mathrm{~d}$, to $104.92 \mu \mathrm{g}^{\circ} \mathrm{g}^{-1} \mathrm{FW}$ and $128.94 \mu \mathrm{g}^{\circ} \mathrm{g}^{-1} \mathrm{FW}$, respectively, which were $55.67 \%$ and $91.31 \%$ higher than that of CK. With the MT pretreatment (T2), the proline contents were always higher than those of $\mathrm{T} 1$, increased by $20.69 \%, 22.89 \%, 12.63 \%, 6.25 \%$ respectively at $3,6,9$, and $12 \mathrm{~d}$. It can be concluded that exogenous melatonin can increase the proline content of kiwifruit under copper stress, enhanced the cell osmotic adjustment and improve the ability of plant adversity resistance.

Table 1 Effects of exogenous melatonin on proline content in leaves of kiwifruit seedlings under copper stress $\left[\mu \mathrm{g} \cdot \mathrm{g}^{-1} \mathrm{FW}\right]$

\begin{tabular}{cccccc}
\hline & $0 \mathrm{~d}$ & $3 \mathrm{~d}$ & $6 \mathrm{~d}$ & $9 \mathrm{~d}$ & $12 \mathrm{~d}$ \\
\hline $\mathrm{CK}$ & $66.99 \pm 5.48 \mathrm{e}$ & $67.26 \pm 3.74 \mathrm{e}$ & $67.40 \pm 3.99 \mathrm{e}$ & $67.84 \pm 3.85 \mathrm{e}$ & $67.26 \pm 5.20 \mathrm{e}$ \\
$\mathrm{T} 1$ & $67.23 \pm 4.35 \mathrm{e}$ & $77.68 \pm 3.95 \mathrm{~d}$ & $104.92 \pm 5.70 \mathrm{~b}$ & $90.07 \pm 4.72 \mathrm{c}$ & $77.16 \pm 3.78 \mathrm{~d}$ \\
$\mathrm{~T} 2$ & $67.90 \pm 2.40 \mathrm{e}$ & $93.75 \pm 3.78 \mathrm{c}$ & $128.94 \pm 5.16 \mathrm{a}$ & $101.45 \pm 4.92 \mathrm{~b}$ & $81.98 \pm 4.79 \mathrm{~d}$ \\
\hline
\end{tabular}

Note: Data with the different letters indicate the difference is significant $(\mathrm{P}<0.05)$. The same as below.

Effects of exogenous melatonin on antioxidant substances in leaves of kiwifruit seedlings under copper stress. As seen from Table 2, the TPC contents of T1 and T2 showed an upward trend, and were significantly higher than CK. At $12 \mathrm{~d}, \mathrm{~T} 1$ and $\mathrm{T} 2$ reached the maximum, and were higher than CK by $194.41 \%$ and $253.42 \%$. The change trends of TFC and TFAC in T1 and T2 were similar, all increased first and then decreased, and reached peaked at $6 \mathrm{~d}$. At $6 \mathrm{~d}$, compared with $\mathrm{CK}$, the content of TFC increased by $20.16 \%, 33.28 \%$; The content of TFAC respectively increased by $25 \%, 50 \%$. However, the TPC, TFC, TFAC of T2 were always higher than T1. Compared with CK, the content of AsA in T1 and T2 decreased firstly and then increased, and reached minimum at $3 \mathrm{~d}$, which were higher by $13.46 \%, 8.68 \%$. At $12 \mathrm{~d}, \mathrm{~T} 1$ and $\mathrm{T} 2$ respectively increased by $52.17 \%, 106.96 \%$, compared with CK. It could be seen that exogenous melatonin increased the antioxidant content of kiwifruit leaves under copper stress.

Effects of exogenous melatonin on antioxidant ability of kiwifruit seedlings under copper stress. Table 3 are the change of antioxidant capacity (DPPH, ABTS, FRAP) of kiwifruit seedlings in the process of copper stress. With the prolongation of copper stress, the antioxidant capacity of the leaves of kiwifruit seedlings in the treatment group decreased and then increased. When compared with CK, at $0-6 \mathrm{~d}$, the DPPH content of T1 and T2 decreased gradually, which were $3.06 \%$ and $2.55 \%$; Then the DPPH content of T1 and T2 increased gradually, which were $31.28 \%$ and $36.92 \%$. The DPPH 
content of T2 is always higher than T1. The trends of ABTS and FRAP were similar to DPPH. The results indicated that exogenous melatonin treatment improved the antioxidant ability of kiwifruit seedlings under copper stress, and enhanced plant resistance to heavy metal stress.

Table 2 Effects of exogenous melatonin on the TPC, TFC, TFAC and AsA content in leaves of kiwifruit seedlings under copper stress $\left[\mathrm{mgGAE} \bullet \mathrm{kg}^{-1} \mathrm{FW}\right]$

\begin{tabular}{ccccccc}
\hline & & $0 \mathrm{~d}$ & $3 \mathrm{~d}$ & $6 \mathrm{~d}$ & $9 \mathrm{~d}$ & $12 \mathrm{~d}$ \\
\hline \multirow{3}{*}{ TPC } & CK & $1.61 \pm 0.03 \mathrm{~h}$ & $1.61 \pm 0.11 \mathrm{~h}$ & $1.60 \pm 0.06 \mathrm{~h}$ & $1.61 \pm 0.06 \mathrm{~h}$ & $1.61 \pm 0.07 \mathrm{~h}$ \\
& T1 & $1.62 \pm 0.08 \mathrm{~h}$ & $2.39 \pm 0.11 \mathrm{~g}$ & $2.64 \pm 0.05 \mathrm{f}$ & $4.19 \pm 0.18 \mathrm{~d}$ & $4.74 \pm 0.06 \mathrm{~b}$ \\
& $\mathrm{~T} 2$ & $1.65 \pm 0.06 \mathrm{~h}$ & $2.44 \pm 0.10 \mathrm{~g}$ & $3.20 \pm 0.09 \mathrm{e}$ & $4.48 \pm 0.03 \mathrm{c}$ & $5.69 \pm 0.10 \mathrm{a}$ \\
\hline \multirow{2}{*}{ TFC } & CK & $6.38 \pm 0.33 \mathrm{~d}$ & $6.40 \pm 0.17 \mathrm{~d}$ & $6.40 \pm 0.01 \mathrm{~d}$ & $6.30 \pm 0.34 \mathrm{~d}$ & $6.40 \pm 0.02 \mathrm{~d}$ \\
& T1 & $6.37 \pm 0.30 \mathrm{~d}$ & $6.90 \pm 0.09 \mathrm{c}$ & $7.69 \pm 0.09 \mathrm{~b}$ & $6.44 \pm 0.07 \mathrm{~d}$ & $4.02 \pm 0.15 \mathrm{f}$ \\
& T2 & $6.39 \pm 0.06 \mathrm{~d}$ & $7.70 \pm 0.12 \mathrm{~b}$ & $8.53 \pm 0.14 \mathrm{a}$ & $7.83 \pm 0.04 \mathrm{~b}$ & $5.70 \pm 0.19 \mathrm{e}$ \\
\hline \multirow{3}{*}{ TFAC } & CK & $0.64 \pm 0.01 \mathrm{ef}$ & $0.63 \pm 0.02 \mathrm{ef}$ & $0.64 \pm 0.01 \mathrm{ef}$ & $0.64 \pm 0.02 \mathrm{ef}$ & $0.64 \pm 0.02 \mathrm{ef}$ \\
& T1 & $0.63 \pm 0.01 \mathrm{ef}$ & $0.64 \pm 0 \mathrm{e}$ & $0.80 \pm 0 \mathrm{c}$ & $0.65 \pm 0 \mathrm{e}$ & $0.62 \pm 0.01 \mathrm{f}$ \\
& T2 & $0.64 \pm 0 \mathrm{ef}$ & $0.65 \pm 0.01 \mathrm{e}$ & $0.96 \pm 0 \mathrm{a}$ & $0.85 \pm 0.03 \mathrm{~b}$ & $0.76 \pm 0.01 \mathrm{~d}$ \\
\hline \multirow{3}{*}{ AsA } & CK & $6.90 \pm 0.19 \mathrm{fg}$ & $6.91 \pm 0.04 \mathrm{fg}$ & $6.95 \pm 0.20 \mathrm{fg}$ & $6.91 \pm 0.09 \mathrm{fg}$ & $6.90 \pm 0.05 \mathrm{fg}$ \\
& T1 & $6.67 \pm 0.08 \mathrm{~g}$ & $5.98 \pm 0.19 \mathrm{i}$ & $7.00 \pm 0.18 \mathrm{ef}$ & $7.49 \pm 0.30 \mathrm{~d}$ & $10.50 \pm 0.27 \mathrm{~b}$ \\
& T2 & $6.76 \pm 0.03 \mathrm{fg}$ & $6.31 \pm 0.08 \mathrm{~h}$ & $7.25 \pm 0.19 \mathrm{de}$ & $9.13 \pm 0.30 \mathrm{c}$ & $14.28 \pm 0.27 \mathrm{a}$ \\
\hline
\end{tabular}

Table 3 Effects of exogenous melatonin on the DPPH, ABTS and FRAP content in leaves of kiwifruit seedlings under copper stress [umol $\mathrm{kg}^{-1} \mathrm{FW}$ ]

\begin{tabular}{ccccccc}
\hline & & $0 \mathrm{~d}$ & $3 \mathrm{~d}$ & $6 \mathrm{~d}$ & $9 \mathrm{~d}$ & $12 \mathrm{~d}$ \\
\hline \multirow{3}{*}{ DPPH } & CK & $1.92 \pm 0.10 \mathrm{e}$ & $1.95 \pm 0.02 \mathrm{e}$ & $1.96 \pm 0.02 \mathrm{e}$ & $1.94 \pm 0.02 \mathrm{e}$ & $1.95 \pm 0.03 \mathrm{e}$ \\
& T1 & $1.95 \pm 0.01 \mathrm{e}$ & $1.92 \pm 0.03 \mathrm{~d}$ & $1.90 \pm 0.05 \mathrm{e}$ & $2.48 \pm 0.16 \mathrm{c}$ & $2.56 \pm 0.13 \mathrm{bc}$ \\
& T2 & $1.96 \pm 0.03 \mathrm{e}$ & $1.94 \pm 0.03 \mathrm{~d}$ & $1.91 \pm 0.08 \mathrm{e}$ & $2.59 \pm 0.03 \mathrm{ab}$ & $2.67 \pm 0.03 \mathrm{a}$ \\
\hline \multirow{3}{*}{ ABTS } & CK & $8.52 \pm 0.08 \mathrm{e}$ & $8.52 \pm 0.08 \mathrm{e}$ & $8.54 \pm 0.09 \mathrm{e}$ & $8.54 \pm 0.07 \mathrm{e}$ & $8.59 \pm 0.05 \mathrm{e}$ \\
& T1 & $8.54 \pm 0.09 \mathrm{e}$ & $5.83 \pm 0.08 \mathrm{~h}$ & $4.82 \pm 0.07 \mathrm{i}$ & $10.49 \pm 0.10 \mathrm{~d}$ & $12.21 \pm 0.13 \mathrm{~b}$ \\
& T2 & $8.57 \pm 0.05 \mathrm{e}$ & $7.82 \pm 0.02 \mathrm{f}$ & $6.93 \pm 0.08 \mathrm{~g}$ & $11.47 \pm 0.12 \mathrm{c}$ & $14.39 \pm 0.12 \mathrm{a}$ \\
\hline \multirow{3}{*}{ FRAP } & CK & $4.94 \pm 0.34 \mathrm{ce}$ & $5.08 \pm 0.38 \mathrm{c}$ & $5.15 \pm 0.18 \mathrm{c}$ & $5.00 \pm 0.21 \mathrm{c}$ & $5.12 \pm 0.45 \mathrm{c}$ \\
& T1 & $5.09 \pm 0.06 \mathrm{c}$ & $4.59 \pm 0.04 \mathrm{e}$ & $3.74 \pm 0.24 \mathrm{~h}$ & $8.48 \pm 0.26 \mathrm{~b}$ & $8.75 \pm 0.35 \mathrm{~b}$ \\
& T2 & $5.16 \pm 0.06 \mathrm{c}$ & $4.90 \pm 0.08 \mathrm{ce}$ & $4.17 \pm 0.17 \mathrm{f}$ & $8.54 \pm 0.33 \mathrm{~b}$ & $10.03 \pm 0.25 \mathrm{a}$ \\
\hline
\end{tabular}

\section{Conclusions}

Under stress, plant cells can accumulation of proline and other osmotic adjustment substances to protect the cell membrane, in order to maintain a high water potential and keep turgor pressure and water content [11]. The results showed that the content of proline increased significantly under the stress of copper. After spraying exogenous melatonin, the content of proline increased significantly. Maintaining the balance of inner and outer water potential prevents excessive cell loss and protects the plant cell membrane, to provide a guarantee for the mitigation of copper stress. 
TPC, TFC, TFAC, AsA are important non enzymatic antioxidant substances in plants. The plant itself can protect the cell from oxidative damage by the non-enzymatic antioxidant system to eliminate excessive reactive oxygen species formed under adverse conditions [12]. When there are antioxidants for hydrogen production (such as phenols), the color of DPPH solution becomes shallow; ABTS ${ }^{\cdot+}$ reacts with it and turn it into a colorless ABTS; And FRAP measures the antioxidant capacity of power by measuring the ability of $\mathrm{Fe}^{3+}$ to be reduced to $\mathrm{Fe}^{2+}$ [13]. The results showed that exogenous melatonin treatment increased the content of TPC, TFC, TFAC, AsA in leaves of kiwifruit seedlings, enhanced the antioxidant ability. It can be concluded that exogenous melatonin can increase the content of antioxidant substances and the antioxidant ability in plants, vigorously scavenging reactive oxygen species, to improve the ability of plants to resist heavy metal stress.

In conclusion, under the condition of copper stress, exogenous melatonin treatment can increase the content of proline in leaves of kiwifruit seedlings, increase cell permeability, improve antioxidant and antioxidant capacity, timely removal free radical, so as to enhance the ability of plants to resist heavy metals.

\section{References}

[1] J.V. Possingham: Kiwifruit science and management: I.J. Warrington and G.C. Weston (Editors). Scientia Horticulture Vol. 1-2, p. 171. (1991)

[2] A.B. Lerner, J.D. Case, and Y. Takahashi: Isolation of melatonin, the pineal gland factor that lightens melanocytes. Am Chen Soc. Vol. 80, p. 2592. (1958)

[3] Y.X. Jiang: Functional analysis of melatonin in plants. Technology Research Vol. 11(12), p. 198. (China 2015)

[4] N. Nagalakshmi and M.N. Prasad: Copper-induced oxidative stress in Scenedesmus bijugatus: Protective role of free radical scavengers. Bull Environ Contam Toxical Vol. 65(5), p. 628. (1998)

[5] H.S. Li: Principle and technology of plant physiology and biochemistry experiment. (Higher Education Press, China 2000)

[6] V.L. Singleton and J.A. Rossi: Colorimetry of total phenols with phosphomolybdic phosphotungstic acid reagents. Am J Enol Viticult Vol. 16, p. 158. (1965)

[7] Z. Jia, M. Tang and J. Wu: The determination of flavonoid contents in mulberry and their scavenging effects on superoxide radicals. Food Chem Vol. 64, p. 559. (1999)

[8] Y.G. Li, G. Tanner and P. Larkin: The DMACA-HCl protocol and the threshold proanthocyanidin content for bloat safety in forage legumes. Sci Food Agr Vol. 70, p. 101. (1996)

[9] G.R. Du: Analysis of antioxidant activity and antioxidant activity of kiwifruit, persimmon and apple fruits. Northwest A\&F University. (China 2009)

[10] F. Ma and L. Cheng: The sun-exposed peel of apple fruit has higher xanthophyll cycle-dependent thermal dissipation and antioxidants of the ascorbate-glutathione pathway than the shaded peel. Plant Science Vol. 165(4), p. 827. (2003)

[11] A. Patakas, N. Nikolaou and E. Zioziou: The role of organic solute and ion accumulation in osmotic adjustment in drought-stressed grapevines. Plant Science Vol. 163(2), p. 367. (2002)

[12] J.H. Hao, Y. Yi and Q.M. Shang: Effects of exogenous salicylic acid on membrance lipid peroxidation and photosynthetic characteristics of Cucumis sativus seedlings under drought stress. Chinese Journal of Applied Ecology Vol. 23(3), p. 723. (China 2012)

[13] A. Bub, B.L. Watzl and H. Delincee: Moderate intervention with carotenoid-rich vegetable products reduces lipid peroxi-dation in men. Journal of Nutrition Vol. 130(9), p. 2200. (2000) 